\title{
PERBANDINGAN METODE EDAS DAN ARAS PADA PEMILIHAN RUMAH DI KOTA PONTIANAK
}

\author{
Dwi Marisa Midyanti ${ }^{1}$, Rahmi Hidyati ${ }^{2}$, Syamsul Bahri ${ }^{3}$ \\ 1,2,3 Fakultas Matematika dan Ilmu Pengetahuan Alam, Universitas Tanjungpura Pontianak \\ Idwi.marisa@siskom.untan.ac.id, ${ }^{2}$ rahmihidayati@siskom.untan.ac.id, ${ }^{3}$ syamsul.bahri@siskom.untan.ac.id
}

Abstrak - Dalam masalah pengambilan keputusan, teknik dan model dari Multi Criteria Decision Making (MCDM) sangat sering digunakan, dan berkembang sangat pesat. Pada penelitian ini menggunakan dua metode MCDM yaitu EDAS dan ARAS pada pemilihan rumah di Kota Pontianak. Metode EDAS didasarkan pada skor penilian (AS) tertinggi untuk mendapatkan pilihan terbaik dari semua alternatif, sedangkan metode ARAS menggunakan nilai utilitas (Ki) tertinggi untuk mendapatkan pilihan terbaik. Data yang digunakan pada penelitian ini berjumlah 30 data perumahan dengan 11 kriteria. Hasil akhir dari penelitian ini menunjukkan bahwa metode EDAS dan ARAS menghasilkan pilihan berbeda pada perangkingan alternatif. Untuk alternatif terbaik pada dengan metode EDAS didapatkan alternatif 9 dengan skor penilaian sebesar 0.7372, sementara dengan metode ARAS alternatif 10 merupakan alternatf terbaik dengan nilai utilitas 1 .

Keywords - EDAS, ARAS, MCDM, Pemilihan Rumah.

Abstract - In the matter of decision making, techniques and models of Multi Criteria Decision Making (MCDM) are very often used, and develop very quickly. In this study using two MCDM methods namely EDAS and ARAS in the selection of houses in Pontianak City. The EDAS method is based on the highest (US) score to get the best choice from all alternatives, while the ARAS method uses the highest utility value (Ki) to get the best choice. The data used in this study prove 30 housing data with 11 criteria. The final results of this study indicate that the EDAS and ARAS methods produce different choices in alternative ranking. For the best alternative with EDAS method, alternative 9 was obtained with the highest score of 0.7372 , while alternative 10 ARAS method was the best alternative with utility value 1.

Keywords- EDAS, ARAS, MCDM, Home Selection.

\section{PENDAHULUAN}

Dalam masalah pengambilan keputusan, teknik dan model dari Multi Criteria Decision Making (MCDM) sangat sering digunakan. Menurut KeshavarazGhorabaee, et all [1] dalam beberapa dekade terakhir, banyak peneliti yang mengusulkan berbagai metode MCDM diantaranya Simple Additive Weighting (SAW), Analytic Hierarchy Process (AHP), ELimination Et ChoixTraduisant la REalité (ELECTRE), Preference Ranking Organization Method for Enrichment of Evaluations (PROMETHEE), Technique for Order of Preference by Similarity to Ideal Solution (TOPSIS), VlseKriterijumskaOptimizacija

KompromisnoResenje (VIKOR) dan Evaluation Based on Distance from Average Solution (EDAS).

EDAS diperkenalkan oleh KeshavarazGhorabaee, et all [2] untuk penyelesaian klasifikasi persediaan multi-kriteria pada perusahaan. Hasil penelitian adalah metode EDAS stabil dalam bobot kriteria yang berbeda dan juga konsisten dengan metode lain yaitu VIKOR, TOPSIS, SAW dan COPRAS berdasarkan koefisien korelasi Spearman.
EDAS pernah digunakan oleh Karabasevic, et all [3] untuk pemilihan personil dalam industry IT. Hasil peneilitan adalah metode EDAS merupakan metode yang efektif, dapat disesuaikan dan mudah digunakan dalam pemilihan personil. EDAS dapat membantu pengambil keputusan untuk memilih kandidat terbaik di antara yang lain.

Pada penelitian ini, akan dibandingkan hasil perangkingan pada metode EDAS dengan hasil perangkingan dari metode Additive Ratio ASsessment (ARAS).

ARAS diperkenalkan oleh Zavadskas dan Turskis pada penelitian [4] dan menggunakan ARAS untuk kasus evaluasi iklim mikro di ruang kantor. Hasilnya model ARAS mudah dalam mengevaluasi dan merangking keputusan alternatif. Prioritas dari alternatif dapat ditentukan sesuai dengan nilai fungsi utilitas.

ARAS digunakan oleh Rostamzadeh, et all [5] untuk pengukuran kinerja manajemen supply chain di perusahaan kecil-menengah dibawah ketidakpastian. Hasil penelitian adalah kualitas pengiriman barang, tingkat kerusakan, tingkat pengembalian barang dan pengiriman penuh dan tepat waktu memperoleh 
prioritas tertinggi. Alternatif ke 3 dalam penelitian ini merupakan alternatif terbaik dalam hal kinerja.

Özbek dan Erol [6] membandingkan metode ARAS dan COPRAS untuk perangkingan perusahaan anjak piutang di Istambul. Hasil penelitian adalah dengan empat tahun data, metode ARAS dan COPRAS memiliki rangking yang sama untuk perusahaan yang paling konsisten yaitu perusahaan GAFRA dan rangking yang sama untuk dua peringkat terakhir yaitu perusahaan SMRFT dan BSRFT.

Pada penelitian ini akan dibandingkan metode ARAS dan COPRAS untuk pemilihan rumah di Kota Pontianak. Data yang digunakan berdasarkan penelitian Alpaniam dan Midyanti [7]. Alpaniam dan Midyanti menggunakan metode TOPSIS untuk perangkingan pemilihan rumah dan menghasilkan rekomendasi terbaik yaitu perumahan Purnama Perdana dengan nilai preferensi 0.848318509 .

\section{METODE PENELITIAN}

Pada penelitian ini metode yang digunakan yaitu metode EDAS dan ARAS. Kedua metode tersebut mendapatkan pilihan terbaik berdasarkan nilai tertinggi dari hasil perhitungan metode.

\section{A. Metode EDAS}

EDAS diperkenalkan oleh KeshavarazGhorabaee, et all pada tahun 2015 [2]. EDAS menyelesaikan permasalahan dengan langkah-langkah sebagai berikut [2] :

1. Pilih kriteria penting yang menggambarkan alternatif.

2. Bangun matriks pengambilan keputusan (X), seperti pada persamaan 1 .

$X=\left[X_{i j}\right]_{n \times m}=\left[\begin{array}{cccc}X_{11} & X_{12} & \cdots & X_{1 m} \\ X_{21} & X_{22} & \cdots & X_{2 m} \\ \vdots & \vdots & \vdots & \vdots \\ X_{n 1} & X_{n 2} & \cdots & X_{n m}\end{array}\right]$

Xij merupakan nilai kinerja alternatif ke-1 pada kriteria ke-j

3. Tentukan solusi rata-rata sesuai dengan kriteria, dengan menggunakan persamaan 2 .

$$
A V=\left[A V_{j}\right]_{1 \times m} \text {. }
$$

dimana :

$$
A V_{j}=\frac{\sum_{i=1}^{n} X_{i j}}{n}
$$

4. Hitung jarak positif dari matriks rata-rata (PDA) dan jarak negatif dari matriks rata-rata (NDA) sesuai jenis kriteria (benefit dan cost) dengan persamaan 4 sampai 9.

$$
P D A=\left[P D A_{i j}\right]_{n \times m},
$$

$$
N D A=\left[N D A_{i j}\right]_{n \times m}
$$

Jika j adalah kriteria benefit gunakan persamaan 6 dan 7 .

$$
\begin{aligned}
P D A_{i j} & =\frac{\max \left(0,\left(X_{i j}-A V_{j}\right)\right)}{A V_{j}} \\
N D A_{i j} & =\frac{\max \left(0,\left(A V_{j}-X_{i j}\right)\right)}{A V_{j}}
\end{aligned}
$$

Jika j adalah kriteria non-benefit gunakan persamaan 8 dan 9 .

$$
\begin{aligned}
P D A_{i j} & =\frac{\max \left(0,\left(A V_{j}-X_{i j}\right)\right)}{A V_{j}} \\
N D A_{i j} & =\frac{\left.\max \left(0,\left(X_{i j}-A V_{j}\right)\right)\right)}{A V_{j}}
\end{aligned}
$$

5. Tentukan jumlah terbobot dari PDA dan NDA untuk semua alternatif dengan persamaan 10 dan 11.

$$
\begin{aligned}
& S P_{i}=\sum_{j=1}^{m} w_{j} P D A_{i j} \\
& S N_{i}=\sum_{j=1}^{m} w_{j} N D A_{i j}
\end{aligned}
$$

6. Normalisasi nilai SP dan SN untuk semua alternatif dengan persamaan 12 dan 13.

$$
\begin{aligned}
N S P_{i} & =\frac{S P_{i}}{\max _{i}\left(S P_{i}\right)} \\
N S N_{i} & =1-\frac{S N_{i}}{\max _{i}\left(S N_{i}\right)}
\end{aligned}
$$

7. Hitung skor penilaian (AS) untuk semua alternatif dengan persamaan 14 .

$$
A S_{i}=\frac{1}{2}\left(N S P_{i}+N S N_{i}\right)
$$

dimana $0 \leq A S_{i} \leq 1$ 
8. Beri peringkat alternatif sesuai nilai penurunan dari skor penilaian (AS). Alternatif dengan nilai AS tertinggi merupakan pilihan terbaik diantara alternatif yang ada.

Page| 121 B. Metode ARAS

ARAS diperkenalkan oleh Zavadskas dan Turskis pada tahun 2010 [4]. ARAS menyelesaikan permasalahan dengan langkah-langkah sebagai berikut [4] :

1. Bentuk matriks pengambilan keputusan (DMM), seperti pada persamaan 15 .

$$
X=\left[\begin{array}{ccccc}
x_{01} & \cdots & x_{0 j} & \cdots & x_{0 n} \\
\vdots & \ddots & \vdots & \ddots & \vdots \\
x_{i 1} & \cdots & x_{i j} & \cdots & x_{i n} \\
\vdots & \ddots & \vdots & \ddots & \vdots \\
x_{m 1} & \cdots & x_{m j} & \cdots & x_{m n}
\end{array}\right] ; \quad i=\overline{0, m} ; j=\overline{1, n}
$$

dimana m merupakan jumlah alternatif dan $m$ merupakan jumlah kriteria yang menggambarkan setiap alternatif, $x_{i j}$ mewakili nilai kinerja $\mathrm{i}$ pada kriteria j.

Jika nilai optimal kriteria j tidak diketahui, maka gunakan persamaan 16 dan 17.

$$
\begin{aligned}
& x_{0 j}=\max _{i} x_{i j}, \text { jika } \max _{i} x_{i j} \text { lebih baik (16) } \\
& x_{0 j}=\min _{i} x_{i j}^{*}, \text { jika } \min _{i} x_{i j}^{*} \text { lebih baik (17) }
\end{aligned}
$$

2. Normalisasi nilai awal. Kriteria dengan nilai maksimum yang dianggap lebih baik dinormalisasi dengan persamaan 18 .

$$
\bar{x}_{i j}=\frac{x_{i j}}{\sum_{i=0}^{m} x_{i j}} \text {. }
$$

Kriteria dengan nilai minimum dianggap lebih baik, dinormalisasi dengan persamaan 19 .

$$
x_{i j}=\frac{1}{x_{i j}^{*}} ; \bar{x}_{i j}=\frac{x_{i j}}{\sum_{i=0}^{m} x_{i j}}
$$

3. Normalisasi matriks terbobot dengan persamaan 20.

$$
\hat{x}_{i j}=\bar{x}_{i j} w_{j} ; i=\overline{0, m} \text {, }
$$

Nilai $w_{j}$ adalah $0<w_{j}<1$ dengan jumlah bobot total sama dengan 1 .

Normalisasi matriks terbobot dapat dilihat pada persamaan 21 .

$$
\hat{X}=\left[\begin{array}{ccccc}
\hat{x}_{01} & \cdots & \hat{x}_{0 j} & \cdots & \hat{x}_{0 n} \\
\vdots & \ddots & \vdots & \ddots & \vdots \\
\hat{x}_{i 1} & \cdots & \hat{x}_{i j} & \cdots & \hat{x}_{i n} \\
\vdots & \ddots & \vdots & \ddots & \vdots \\
\hat{x}_{m 1} & \cdots & \hat{x}_{m j} & \cdots & \hat{x}_{m n}
\end{array}\right] ; \quad i=\overline{0, m} ; j=\overline{1, n}
$$

4. Tentukan nilai optimasi $S_{i}$ dengan persamaan 22 .

$$
S_{i}=\sum_{j=1}^{n} \hat{x}_{i j} ; i=\overline{0, m}
$$

5. Tentukan tingkat utilitas Ki setiap alternatif dengan persamaan 23 .

$$
K_{i}=\frac{S_{i}}{S_{0}} ; i=\overline{0, m}
$$

$\mathrm{S}_{\mathrm{i}}$ dan $\mathrm{S}_{0}$ merupakan nilai kriteria optimasi

Nilai $K_{i}$ berada dalam interval $[0,1]$ dan nilai $K_{i}$ terbesar merupakan nilai prioritas.

\section{HASIL DAN PEMBAHASAN}

Penelitian ini menggunakan 11 kriteria dengan 30 alternatif. Kriteria dari penelitian dapat dilihat pada tabel I.

TABEL I KRITERIA PEMILIHAN RUMAH

\begin{tabular}{|l|l|l|r|}
\hline No & \multicolumn{1}{|c|}{ Alternatif } & $\begin{array}{c}\text { Tipe } \\
\text { (Benefit / Cost) }\end{array}$ & $\begin{array}{c}\text { Bobot } \\
\text { Konversi }\end{array}$ \\
\hline 1 & Rumah ibadah & Benefit & 0.0398 \\
\hline 2 & Pos satpam & Benefit & 0.0398 \\
\hline 3 & Pinggir Kota & Benefit & 0.0162 \\
\hline 4 & Pusat Kota & Benefit & 0.0279 \\
\hline 5 & Harga & Cost & 0.1708 \\
\hline 6 & Luas Tanah & Benefit & 0.2904 \\
\hline 7 & Tipe & Benefit & 0.1399 \\
\hline 8 & Air Sumur & Benefit & 0.0058 \\
\hline 9 & PDAM & Benefit & 0.0383 \\
\hline 10 & Kamar tidur & Benefit & 0.1399 \\
\hline 11 & Kamar mandi & Benefit & 0.0913 \\
\hline
\end{tabular}

\section{Perhitungan Metode EDAS}

Data yang digunakan sebagai inputan adalah 30 data perumahan. Matriks data yang digunakan adalah berukuran 30 x 11. Solusi rata-rata sesuai dengan kriteria (AV) dihitung dengan persamaan 3.

TABEL II

SOLUSI RATA-RATA SESUAI DENGAN KRITERIA (AV)

\begin{tabular}{|l|r|}
\hline Kriteria & \multicolumn{1}{|c|}{ AV } \\
\hline K1 & 0.367 \\
\hline K2 & 0.533 \\
\hline K3 & 0.567 \\
\hline K4 & 0.433 \\
\hline K5 & 234666666.667 \\
\hline K6 & 148.533 \\
\hline K7 & 43.9 \\
\hline
\end{tabular}




\begin{tabular}{|l|r|}
\hline K8 & 0.4 \\
\hline K9 & 0.6 \\
\hline K10 & 1.7 \\
\hline K11 & 1.0667 \\
\hline
\end{tabular}

Page | 122 Setelah hasil AV didapat, perhitungan dilanjutkan dengan menggunakan persamaan 4 sampai 9 . Hasil dari langkah 5 sampai dengan langkah 7 dapat dilihat pada tabel III.

TABEL III

JUMLAH TERBOBOT, NORMALISASI SP-SN, DAN SKOR PENILAIAN (AS)

\begin{tabular}{|c|c|c|c|c|}
\hline \multicolumn{2}{|c|}{ Langkah 5} & \multicolumn{2}{|c|}{ Langkah 6} & \multirow{2}{*}{$\mathbf{A S i}$} \\
\hline Spi & Sni & NSPi & NSNi & \\
\hline 0.1589 & 0.1603 & 0.2924 & 0.4736 & 0.3830 \\
\hline 0.1441 & 0.2189 & 0.2653 & 0.2810 & 0.2731 \\
\hline 0.1037 & 0.1159 & 0.1909 & 0.6195 & 0.4052 \\
\hline 0.0984 & 0.1420 & 0.1811 & 0.5335 & 0.3573 \\
\hline 0.1286 & 0.1368 & 0.2367 & 0.5506 & 0.3937 \\
\hline 0.0935 & 0.2424 & 0.1721 & 0.2039 & 0.1880 \\
\hline 0.1308 & 0.1767 & 0.2407 & 0.4196 & 0.3302 \\
\hline 0.1539 & 0.1252 & 0.2832 & 0.5887 & 0.4360 \\
\hline 0.4269 & 0.0948 & 0.7856 & 0.6888 & 0.7372 \\
\hline 0.5434 & 0.2333 & 1.0000 & 0.2337 & 0.6168 \\
\hline 0.3812 & 0.2530 & 0.7015 & 0.1692 & 0.4353 \\
\hline 0.3030 & 0.1444 & 0.5576 & 0.5257 & 0.5417 \\
\hline 0.3103 & 0.1007 & 0.5710 & 0.6691 & 0.6201 \\
\hline 0.2102 & 0.1996 & 0.3868 & 0.3446 & 0.3657 \\
\hline 0.1044 & 0.2502 & 0.1922 & 0.1782 & 0.1852 \\
\hline 0.1757 & 0.0896 & 0.3233 & 0.7059 & 0.5146 \\
\hline 0.1168 & 0.1387 & 0.2149 & 0.5445 & 0.3797 \\
\hline 0.0959 & 0.3045 & 0.1764 & 0.0000 & 0.0882 \\
\hline 0.1578 & 0.2903 & 0.2904 & 0.0466 & 0.1685 \\
\hline 0.1882 & 0.1418 & 0.3464 & 0.5344 & 0.4404 \\
\hline 0.1316 & 0.1913 & 0.2422 & 0.3717 & 0.3069 \\
\hline 0.0937 & 0.2607 & 0.1724 & 0.1439 & 0.1582 \\
\hline 0.1616 & 0.1944 & 0.2974 & 0.3615 & 0.3294 \\
\hline 0.2730 & 0.1535 & 0.5023 & 0.4958 & 0.4991 \\
\hline 0.1988 & 0.1502 & 0.3659 & 0.5066 & 0.4362 \\
\hline 0.1864 & 0.1865 & 0.3430 & 0.3875 & 0.3652 \\
\hline 0.2279 & 0.1093 & 0.4195 & 0.6409 & 0.5302 \\
\hline 0.0755 & 0.2782 & 0.1389 & 0.0862 & 0.1125 \\
\hline 0.1125 & 0.2156 & 0.2071 & 0.2919 & 0.2495 \\
\hline 0.0886 & 0.2763 & 0.1630 & 0.0926 & 0.1278 \\
\hline
\end{tabular}

Hasil akhir perhitungan menggunakan metode EDAS berupa pengurutan skor penilaian (ASi) dari nilai tertinggi sampai terendah. Pengurutan pemilihan rumah berdasarkan metode EDAS dapat dilihat pada tabel IV. Pada tabel IV terlihat bahwa alternatif terbaik dengan menggunakan metode EDAS adalah alternatif 9.
TABEL IV

HASIL EDAS UNTUK PEMILIHAN RUMAH

\begin{tabular}{|c|c|c|}
\hline Peringkat & Alternatif & $\mathbf{A S i}$ \\
\hline 1 & A9 & 0.7372 \\
\hline 2 & A13 & 0.6201 \\
\hline 3 & A10 & 0.6168 \\
\hline 4 & A12 & 0.5417 \\
\hline 5 & A27 & 0.5302 \\
\hline 6 & A16 & 0.5146 \\
\hline 7 & A24 & 0.4991 \\
\hline 8 & A20 & 0.4404 \\
\hline 9 & A25 & 0.4362 \\
\hline 10 & A8 & 0.4360 \\
\hline 11 & A11 & 0.4353 \\
\hline 12 & A3 & 0.4052 \\
\hline 13 & A5 & 0.3937 \\
\hline 14 & A1 & 0.3830 \\
\hline 15 & A17 & 0.3797 \\
\hline 16 & A14 & 0.3657 \\
\hline 17 & A26 & 0.3652 \\
\hline 18 & A4 & 0.3573 \\
\hline 19 & A7 & 0.3302 \\
\hline 20 & A23 & 0.3294 \\
\hline 21 & A21 & 0.3069 \\
\hline 22 & A2 & 0.2731 \\
\hline 23 & A29 & 0.2495 \\
\hline 24 & A6 & 0.1880 \\
\hline 25 & A15 & 0.1852 \\
\hline 26 & A19 & 0.1685 \\
\hline 27 & A22 & 0.1582 \\
\hline 28 & A30 & 0.1278 \\
\hline 29 & A28 & 0.1125 \\
\hline 30 & A18 & 0.0882 \\
\hline
\end{tabular}

\section{Perhitungan Metode ARAS}

Untuk perhitungan dengan metode ARAS, digunakan persamaan 15 sampai 23. Data di normalisasi terlebih dahulu kemudian dikalikan dengan bobot setiap kriteria. Normalisasi matriks terbobot kemudian dijumlahkan untuk menentukan nilai optimasi Si. Setelah didapat $\mathrm{Si}$, hitung tingkat utilitas Ki dengan persamaan 23. Hasil dari nilai optimasi Si dan nilai utilitas Ki dapat dilihat pada tabel $\mathrm{V}$.

TABEL V

NILAI OPTIMASI DAN UTILITAS SETIAP ALTERNATIF

\begin{tabular}{|c|c|c|}
\hline Alternatif & $\mathbf{S i}$ & $\mathbf{K i}$ \\
\hline A1 & 0.0304 & 0.6751 \\
\hline A2 & 0.0233 & 0.5183 \\
\hline A3 & 0.0285 & 0.6321 \\
\hline A4 & 0.0257 & 0.5711 \\
\hline A5 & 0.0260 & 0.5773 \\
\hline A6 & 0.0214 & 0.4759 \\
\hline A7 & 0.0250 & 0.5548 \\
\hline A8 & 0.0276 & 0.6138 \\
\hline A9 & 0.0398 & 0.8843 \\
\hline A10 & 0.0450 & 1.0000 \\
\hline
\end{tabular}




\begin{tabular}{|l|l|l|}
\hline A11 & 0.0375 & 0.8330 \\
\hline A12 & 0.0368 & 0.8178 \\
\hline A13 & 0.0371 & 0.8232 \\
\hline A14 & 0.0320 & 0.7109 \\
\hline A15 & 0.0212 & 0.4701 \\
\hline A16 & 0.0312 & 0.6941 \\
\hline A17 & 0.0280 & 0.6222 \\
\hline A18 & 0.0188 & 0.4166 \\
\hline A19 & 0.0289 & 0.6427 \\
\hline A20 & 0.0264 & 0.5866 \\
\hline A21 & 0.0236 & 0.5241 \\
\hline A22 & 0.0197 & 0.4366 \\
\hline A23 & 0.0242 & 0.5386 \\
\hline A24 & 0.0291 & 0.6460 \\
\hline A25 & 0.0271 & 0.6016 \\
\hline A26 & 0.0250 & 0.5548 \\
\hline A27 & 0.0292 & 0.6481 \\
\hline A28 & 0.0191 & 0.4236 \\
\hline A29 & 0.0225 & 0.5006 \\
\hline A30 & 0.0191 & 0.4250 \\
\hline
\end{tabular}

Hasil akhir perhitungan menggunakan metode ARAS berupa pengurutan nilai utilitas $(\mathrm{Ki})$ dari nilai tertinggi sampai terendah. Pengurutan pemilihan rumah berdasarkan metode ARAS dapat dilihat pada tabel V. Berdasarkan tabel VI didapat alternatif terbaik dengan menggunakan metode ARAS adalah alternatif 10.

TABEL VI

HASIL ARAS UNTUK PEMILIHAN RUMAH

\begin{tabular}{|c|c|c|}
\hline Peringkat & Alternatif & $\mathbf{K i}$ \\
\hline 1 & A10 & 1 \\
\hline 2 & A9 & 0.8843 \\
\hline 3 & A11 & 0.8330 \\
\hline 4 & A13 & 0.8232 \\
\hline 5 & A12 & 0.8178 \\
\hline 6 & A14 & 0.7109 \\
\hline 7 & A16 & 0.6941 \\
\hline 8 & A1 & 0.6751 \\
\hline 9 & A 27 & 0.6481 \\
\hline 10 & A24 & 0.6460 \\
\hline 11 & A19 & 0.6427 \\
\hline 12 & A3 & 0.6321 \\
\hline 13 & A17 & 0.6222 \\
\hline 14 & A8 & 0.6138 \\
\hline 15 & A25 & 0.6016 \\
\hline 16 & A20 & 0.5866 \\
\hline 17 & A5 & 0.5773 \\
\hline 18 & $\mathrm{~A} 4$ & 0.5711 \\
\hline 19 & A7 & 0.5548 \\
\hline 20 & A26 & 0.5548 \\
\hline 21 & A23 & 0.5386 \\
\hline
\end{tabular}

\begin{tabular}{|c|c|c|}
\hline 22 & A21 & 0.5241 \\
\hline 23 & A2 & 0.5183 \\
\hline 24 & A29 & 0.5006 \\
\hline 25 & A6 & 0.4759 \\
\hline 26 & A15 & 0.4701 \\
\hline 27 & A22 & 0.4366 \\
\hline 28 & A30 & 0.4250 \\
\hline 29 & A28 & 0.4236 \\
\hline 30 & A18 & 0.4166 \\
\hline
\end{tabular}

E. Perbandingan Hasil dari metode EDAS dan ARAS

Dari tabel V dan tabel VI dapat diketahui bahwa metode EDAS dan ARAS menghasilkan pilihan berbeda untuk peringkat terbaik. Metode EDAS menghasilkan alternatif 9 dengan nilai skor penilaian (ASi) sebesar 0.7372 sebagai yang terbaik, sementara metode ARAS menghasilkan alternatif 10 dengan nilai utilitas (Ki) sebesar 1 sebagai alternatif terbaik. Alternatif 9 adalah perumahan Indah Lestari dan alternatif 10 adalah perumahan Purnama Perdana.

EDAS dan ARAS memiliki pilihan perumahan yang sama pada peringkat 12, 18, 19, 28,29 dan 30 . Pada dasarnya, kedua metode yang digunakan dapat digunakan untuk pengambilan keputusan pemilihan rumah berdasarkan kriteria dan bobot yang diinginkan.

\section{KESIMPULAN}

Pada penelitian ini digunakan dua metode yaitu EDAS dan ARAS untuk pemilihan rumah di Kota Pontianak. Data yang digunakan berjumlah 30 data dengan 11 kriteria. Metode EDAS didasarkan pada skor penilian (AS) tertinggi untuk mendapatkan pilihan terbaik dari semua alternatif, sedangkan metode ARAS menggunakan nilai utilitas (Ki) tertinggi untuk mendapatkan pilihan terbaik. Metode EDAS dan ARAS menghasilkan pilihan berbeda pada perangkingan alternatif. Untuk alternatif terbaik pada dengan metode EDAS didapatkan alternatif 9 dengan skor penilaian sebesar 0.7372, sementara dengan metode ARAS alternatif 10 merupakan alternatf terbaik dengan nilai utilitas 1 . Terdapat beberapa kesamaan peringkat pemilihan rumah pada kedua metode ini yaitu untuk peringkat 12, 18, 19, 28,29 dan 30 .

Metode EDAS dan ARAS dapat digunakan untuk pengambilan keputusan dalam pemilihan rumah.

\section{REFERENSI}

[1] Keshavarz-Ghotabaee, M., et all., "A Comparative Analysis Of The Rank Reversal Phenomenon In The EDAS And TOPSIS Methods," Economic Computation and Economic Cybernetics Studies and Research, vol. 52, pp. 121-134. 2018.

[2] Keshavarz-Ghotabaee, M., et all., "Multi-Criteria Inventory Classification Using a New Method of Evaluation Based on Distance from Average Solution (EDAS)," INFORMATICA, vol. 26, No 3, pp. 435-451. 2015.

[3] Karabasevic, D., et all., "An Approach to Personnel Selection in the IT Industry Based on the EDAS Method", Transformations in Business \& Economics, vol. 17, No 2 (44), pp.54-65. 2018. 
[4] Zavadskas, E.K., \& Turskis, Z., “A new additive ratio assessment (ARAS) method in multicriteria decision-making," Technological and Economic Development of Economy, vol. 16(2), pp. 159-172. 2010.

[5] Rostamzadeh, R. E., A., et all., "A Fuzzy Aras Method for Supply Chain Management Performance Measurement in SMEs under Uncertainty", Transformations in Business \& Economics, Vol. 16, No 2A (41A), pp.319-348. 2017.

[6] Özbek, A., \& Erol, E., "Ranking of Factoring Companies in Accordance with ARAS and COPRAS Methods," International Journal of Academic Research in Accounting, Finance and Management Sciences, vol. 7(2), pp. 105-116. 2017

[7] Alpaniam \& Midyanti, D.M., “Aplikasi Pemilihan Rumah Di Kota Pontianak Menggunakan Metode TOPSIS Berbasis Web," Jurnal Coding Sistem Komputer Untan, vol. 6(03), pp. 161-172. 2018 